\title{
اختراق النظام المصرفي في مرحلة مناسبة من مراحل تبيض الأموال
}

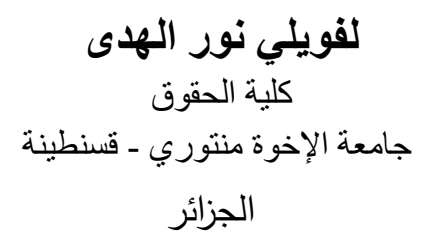

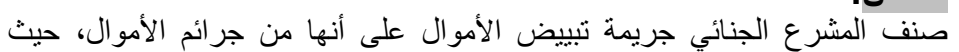

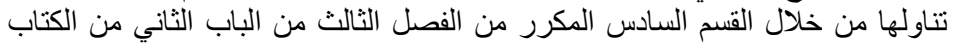

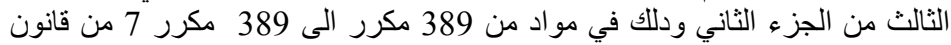

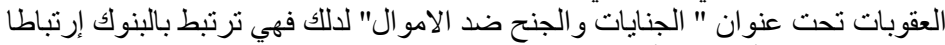

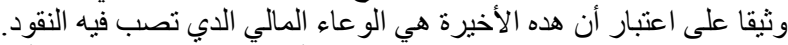

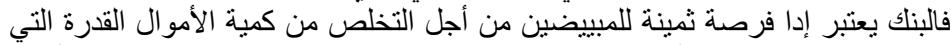

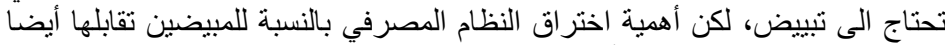

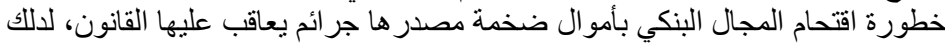

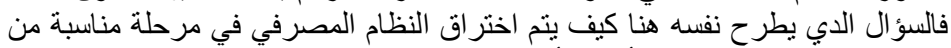

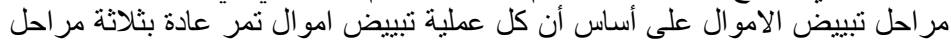

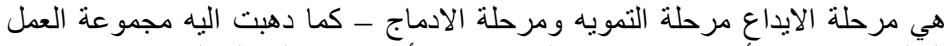

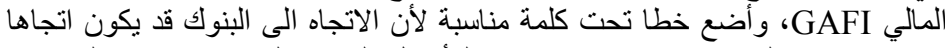

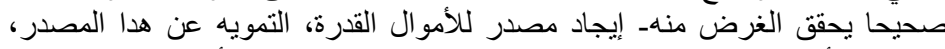

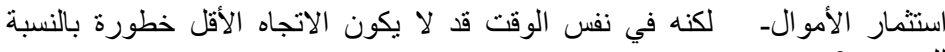

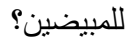
إن أُهمية طرح هدا السؤال يكمن في ضرورة فهم دورة تبييض الاموال بالنسبة لكل

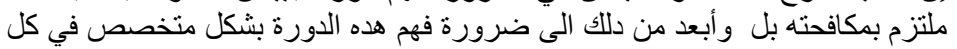

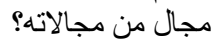

\section{Abstract:}

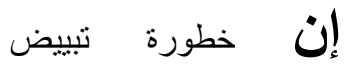
الأموال عن طريق البنوك هي خطورة تضاهي أهمية

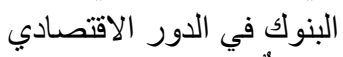

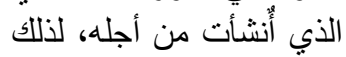

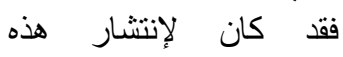
الجريمة رد فعل نتريعي واضح إنعكس من خلال ردل فيري تدخل المشرع بوضع

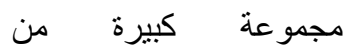
النصوص القانونية

لمحاصرة تنفيذ العملية. لكن هذا التدخل يمكن أن نصفه أيضا بغير المنتظم

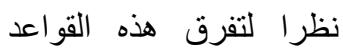
القانونية بين عدة قو انين
Class criminal legislator crime of money laundering as much money crimes, where addressed through Section VI refined from Chapter III of Title II of Book III of Part II and knead in the articles of the 389 repeater to repeater 389 bis 7 of the Penal Code under the title of " crimes and misdemeanors against money " to the rules of engagement are linked to banks closely related to this topic on the grounds that the latter is financial pot where my father poured money.

The bank is Ida precious opportunity to Mbabin order to get rid of the amount of money the ability that you need to whitening, but the importance of penetrating the banking system for Mbabin matched also the seriousness of the banking field to break into a huge money sourced crimes punishable by law, to knead question my parents arises here how to penetrate the banking system in the appropriate stage of money laundering on the basis that all the money laundering process usually go through three stages is the stage of the placement stage, camouflage and stage of integration - as Dhpt him FATF GAFI, and I put a line under an appropriate word because trend to banks may be a trend right achieves its purpose - find a source of funds capability, camouflage for Hedda source, investment Alamwal- but at the same time the trend may not be the least dangerous for ovaries?

The importance put Hedda question lies in the need to understand the cycle of money laundering for each is committed to fight it even further than the rules of engagement need to understand this topic session is a specialist in each of its fields?.

(C) جامعة الإخوة منتوري قسنطينة، الجز ائر 
بشكل يصعب أحبانا الجمع بين محتوياتها خاصة إذا تعلق الأمر بقو اعد قانونية بقتضيها خطورة الوضع.

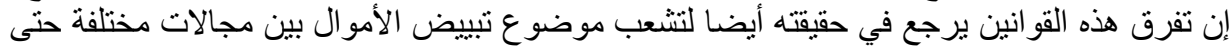

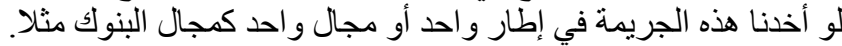

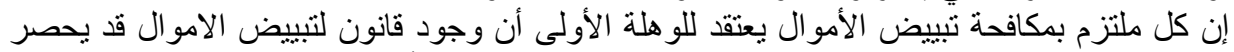

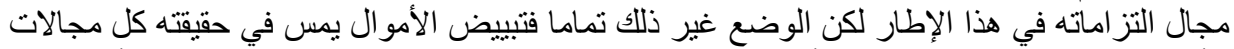

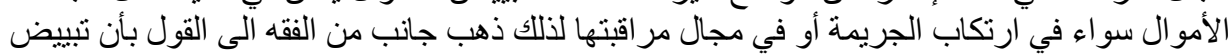

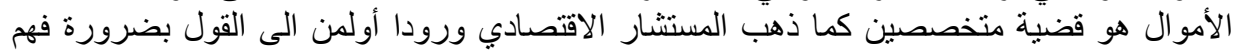
دورة تبييض الأمو ال من أجل إفنشال مخططات هده الدال الدورة.

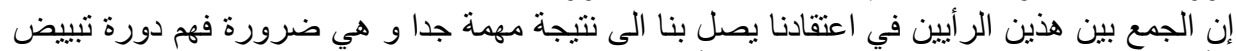

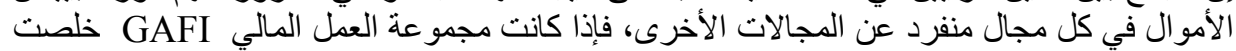

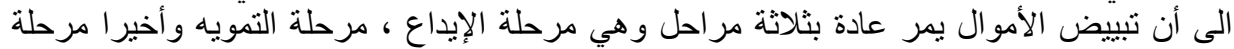

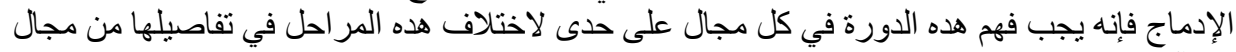

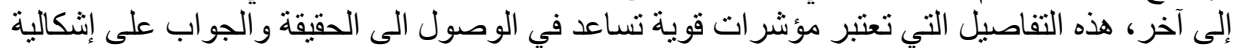

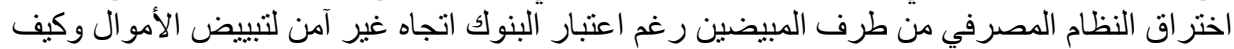

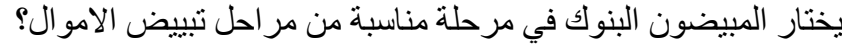
المبحث الأول: البنوك اتجاه غير فر آمن لإيداع الأموال

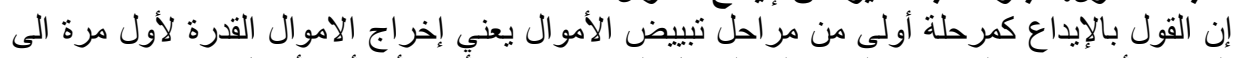

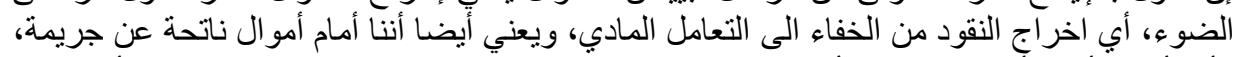

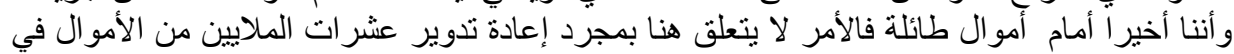

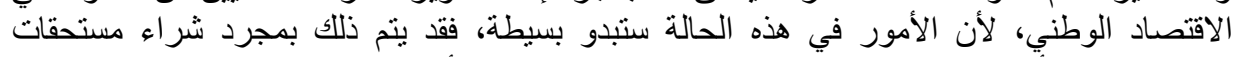

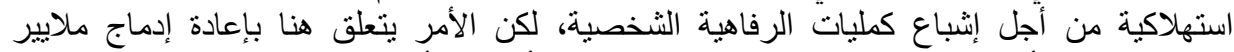

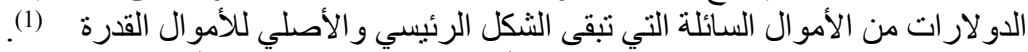

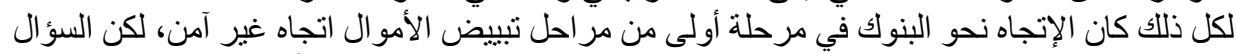

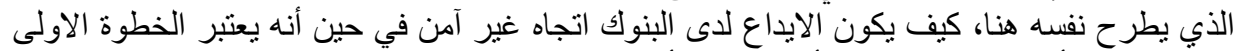

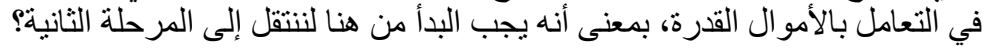

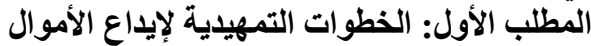

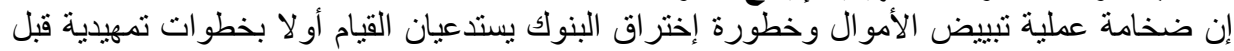

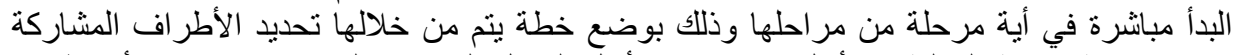

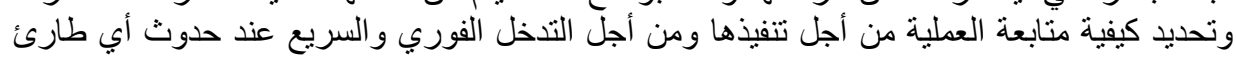

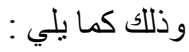

الفرع الأول: التخطيط

ويقصد بالتخطيط الرسم التصوري للعملية برمتها ، من حيث البرنامج الزمني، الذي يستغرقه تنفيذها

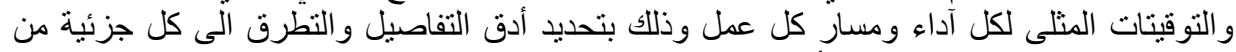

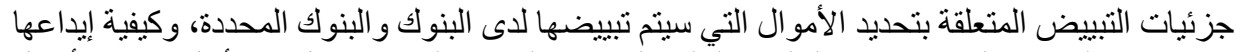

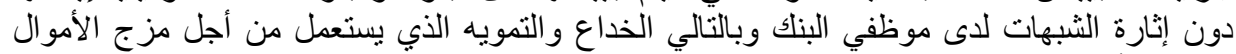

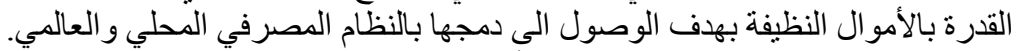

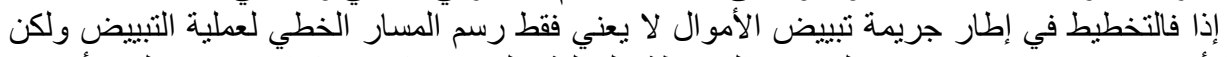

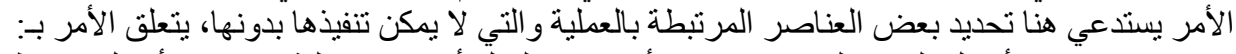

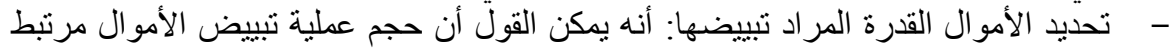

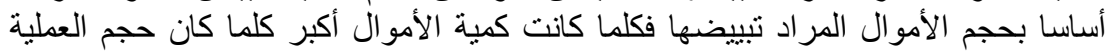

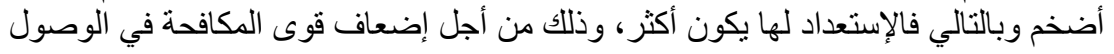


الى الحقيقة، التي لا تعني فقط في هذا الإطار كثف العملية وبالتالي مصادرة الأموال موضوع التبييض والقبض على القائمين بها بل قد تتعداها للوصول التهل التى الجرائم المصدر

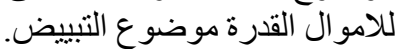

لللك كان من أهم عناصر التخطيط لعملية تبيضض الأموال تحديد كمية الأمو ال القدرة المراد

تبييضها.

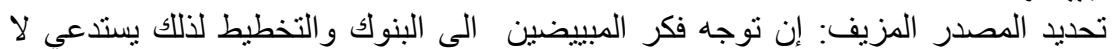

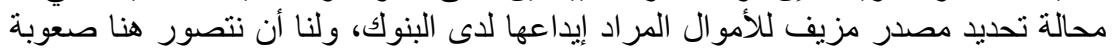

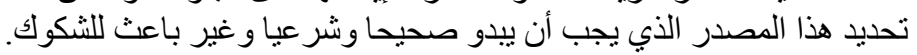

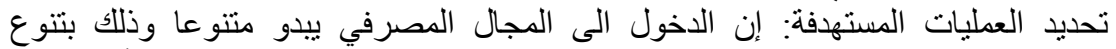

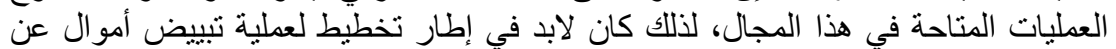

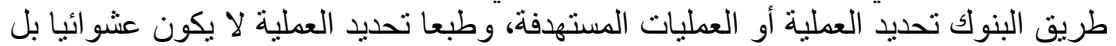

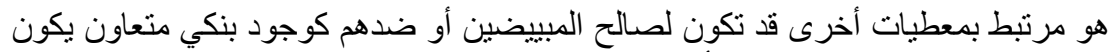

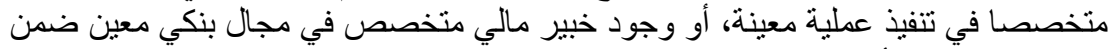

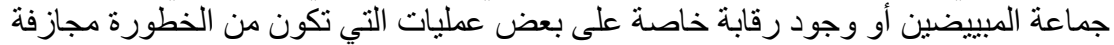
الاخول فيها في بلد التبييض أو الو ل...

- - إخفاء شخصية المالك الحقيقي : تكمن النقطة الأساسية في تحديد اطر اف التنفيذ في إخفاء شخصية المجرم الحقيقي وذلك بتقيم شخصيات أخرى تقوم بتنفيذ العملية تبدو التئي

شخصيات نظيفة و محل ثقية.

إن إخفاء شخصية مالك الأموال الحقيقي هو الأساس المعتمد في كل عمليات التنبيض

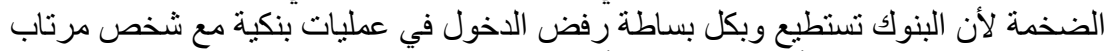

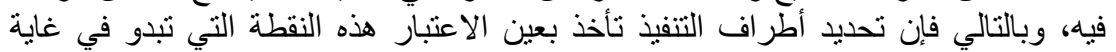

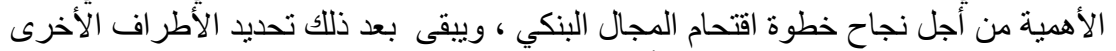

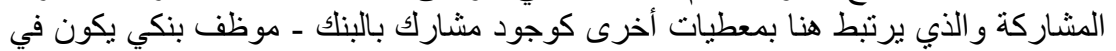

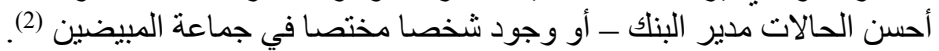

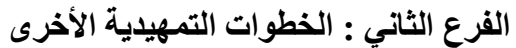

يستدعي التمعيد لعملية تبييض الأمو ال القيام بخطو ات تمهيدية أخرى كما يلي:

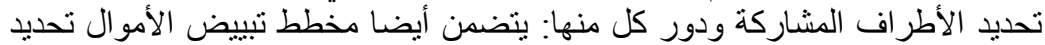

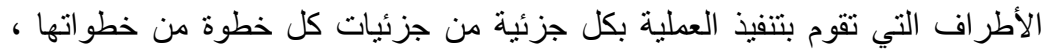

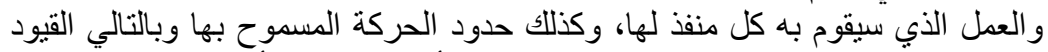

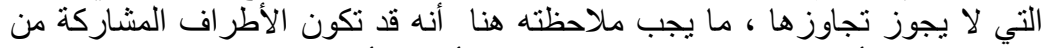

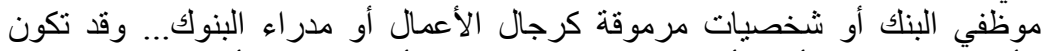

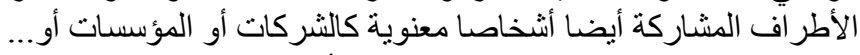

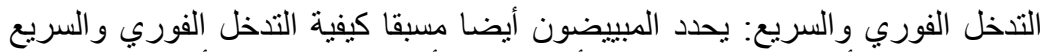

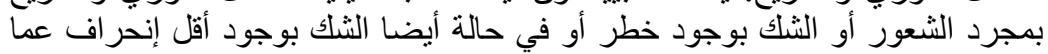

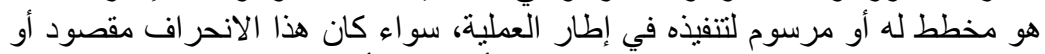

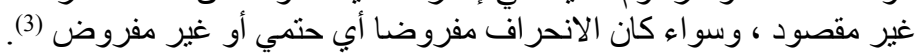

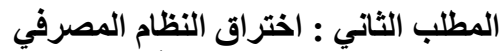

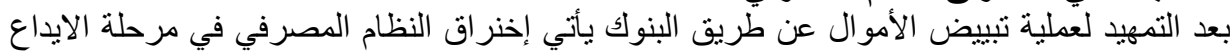

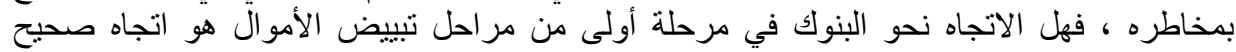




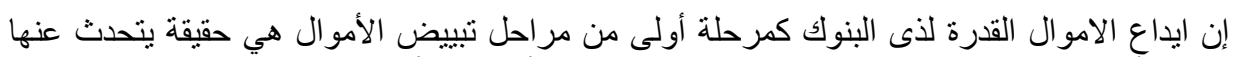

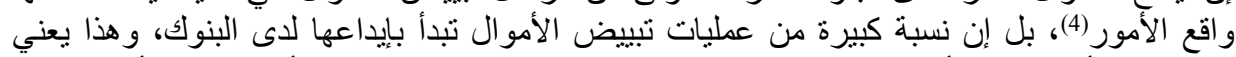

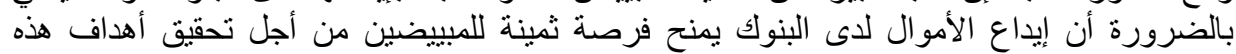

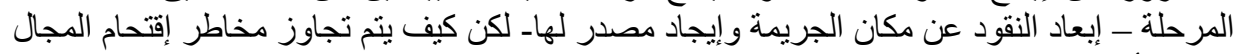

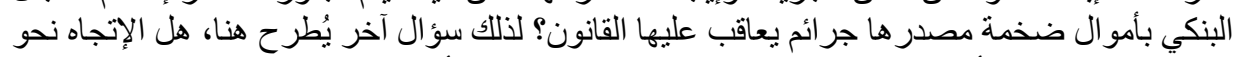

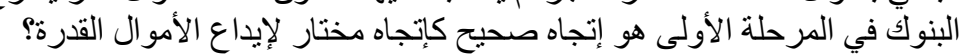

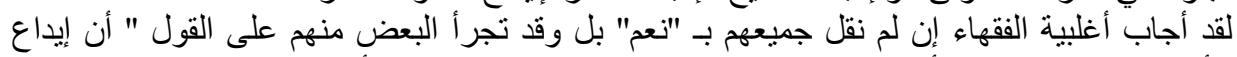

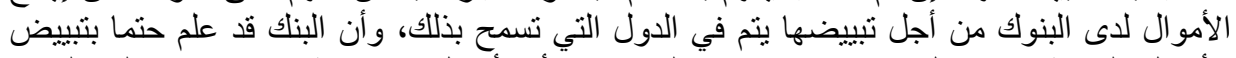

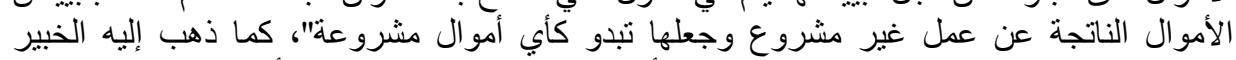

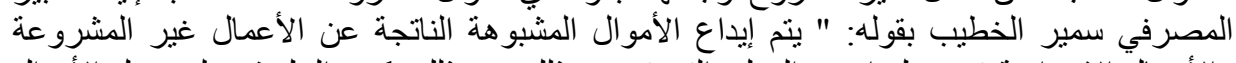

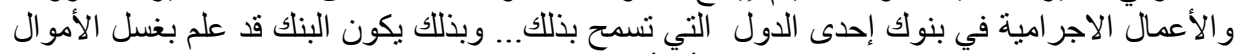

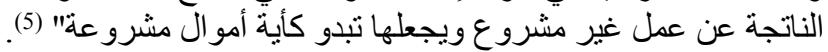

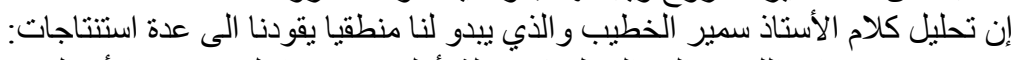

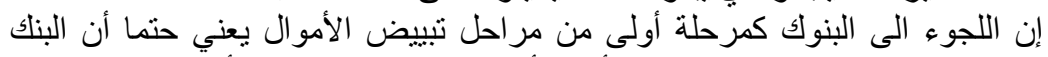

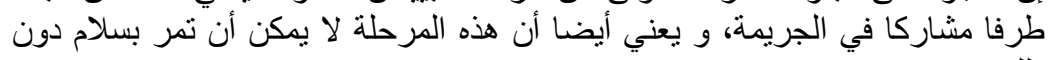

إن التحقيق في عملية تبيض أموال تمت بايداع أمو ال لدى البنوك " كمرحلة أولى" يتجه

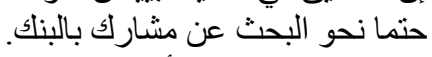

- -

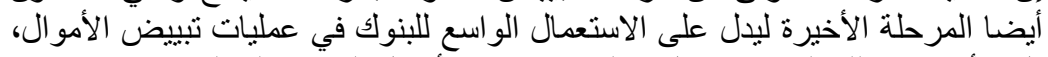

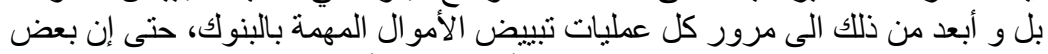

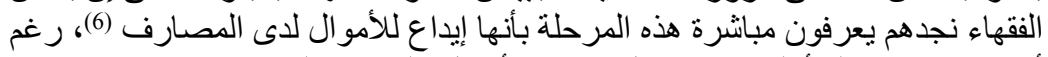

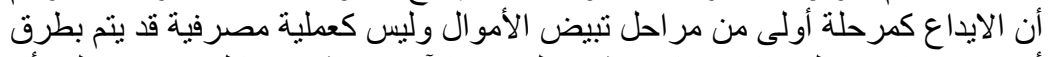

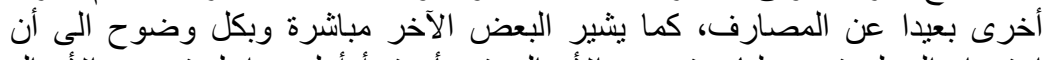

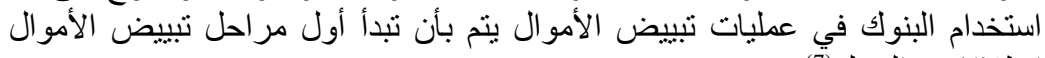

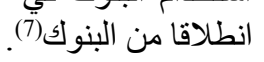

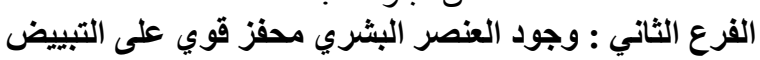

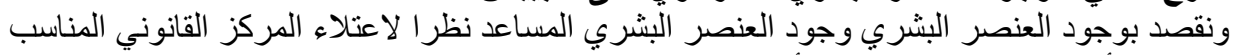

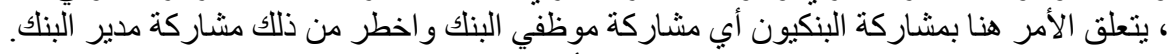

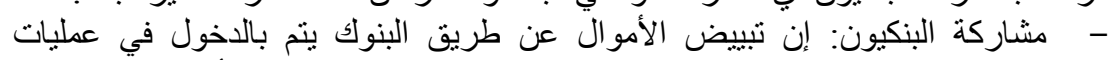

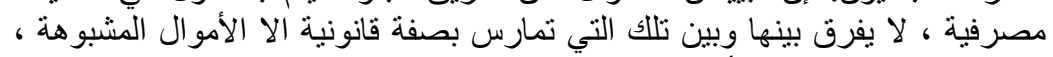

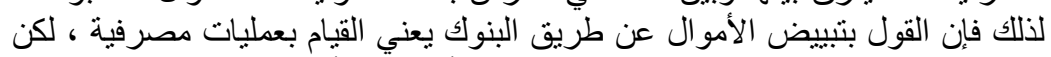

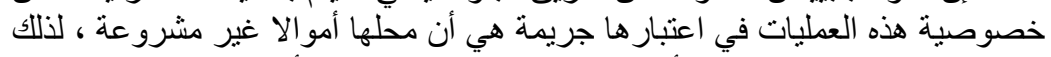

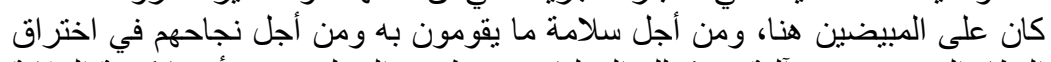

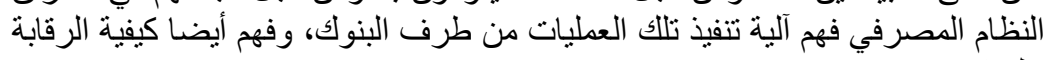

إن الوصول الى نتيجة مرضية في هذا الإطار يعني حتما أن يكون من بين المشاركين

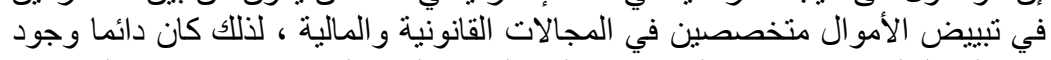

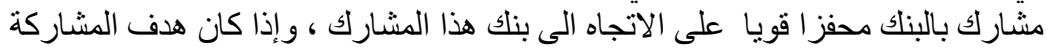

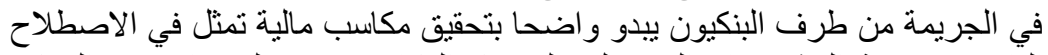
القانوني جريمة الرشوة فإن الحصول على هذه المكاسب قد يختلف باختلاف المركز 
القانوني لكل مشارك ، و الذي يتحدد من خلاله أيضا دوره الرئيسي أو المكمل في تنفيذ

لقد صنف المشرع الجزائري من خلال قانون 06-01 المؤرخ في 20 فيفري 2006

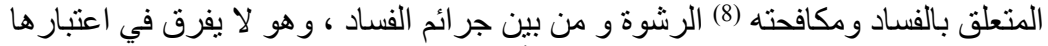

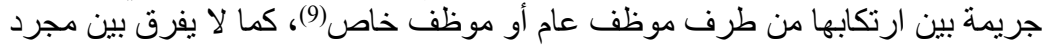

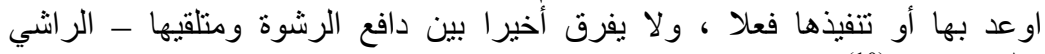
والمرتثي - (10).

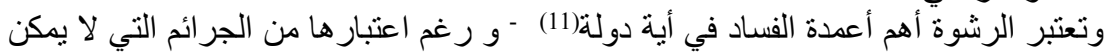

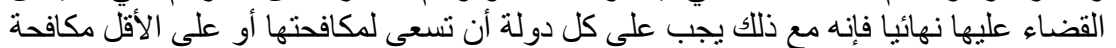

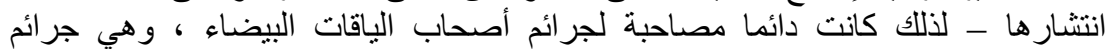

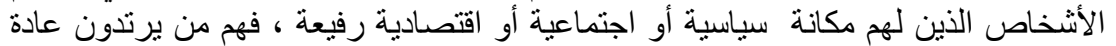

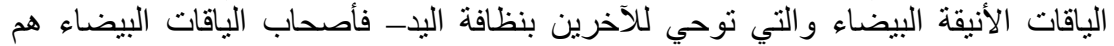

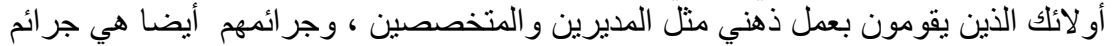

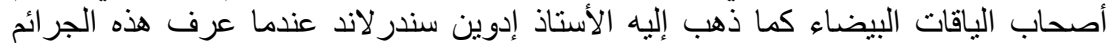

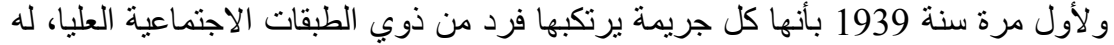

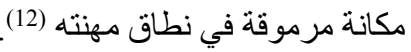
إنه من الخصائص الخطيرة لهذه الجئه الجئه ائم أن القائمين بها يمكنهم الجمع بين السلوك القانوني

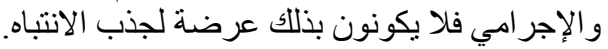

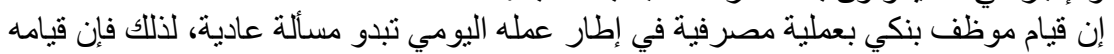

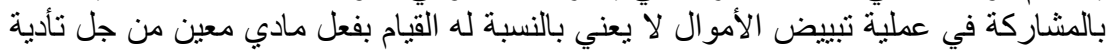

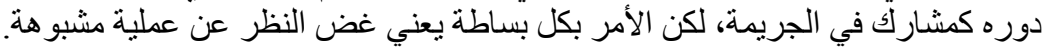

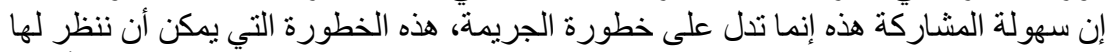

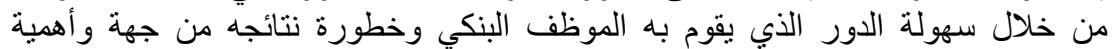

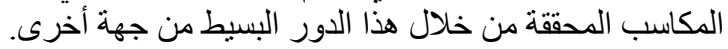

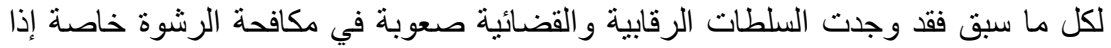

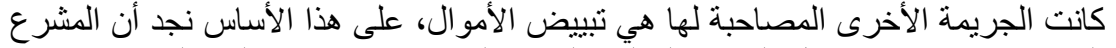

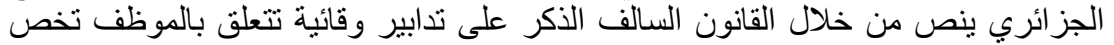

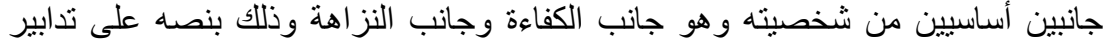
التوظيف وتدابير التصريح بالمنتلكات. تدابير التوظيف:

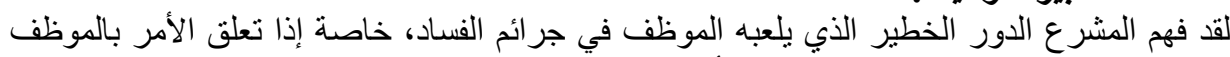

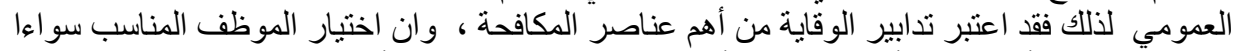

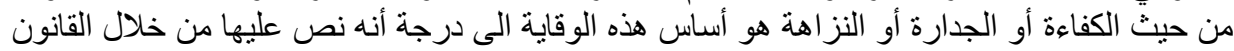

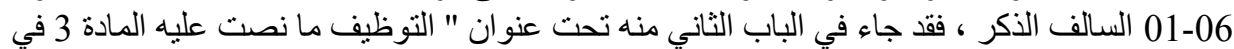

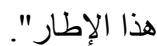

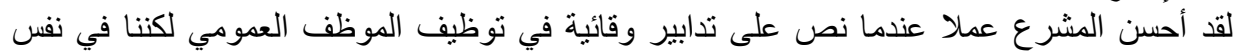

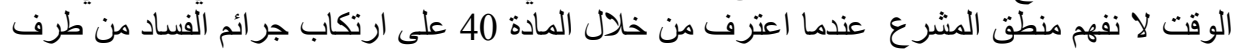

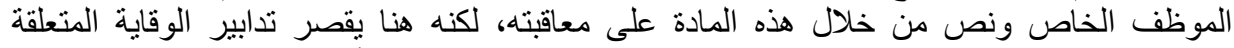

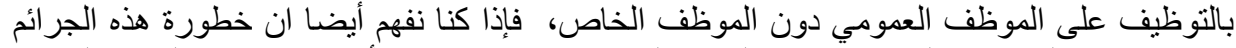

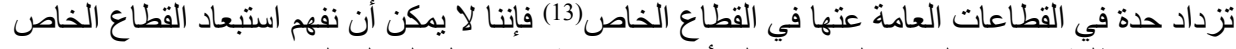

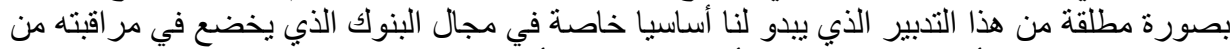
طرف الدولة لنفس الأحكام، سو اء تعلق الأمر بينوك عامة أو بنوك خاصة. 


\section{تدابير التصريح بالممتكات}

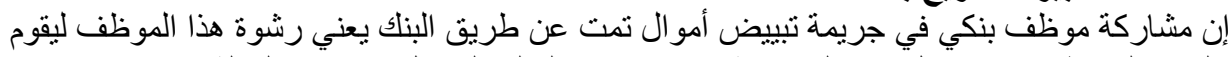

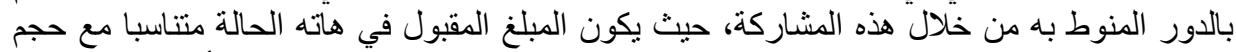

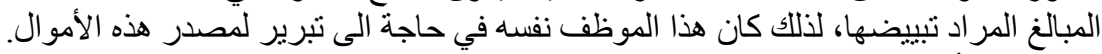

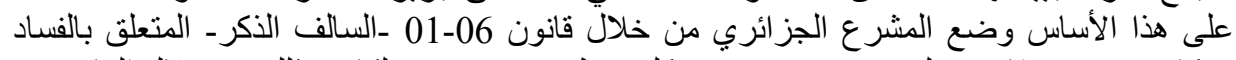

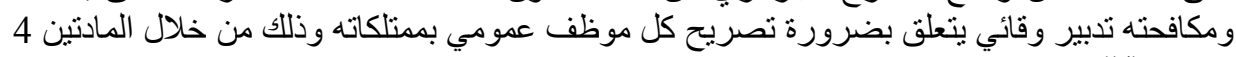

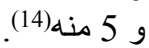

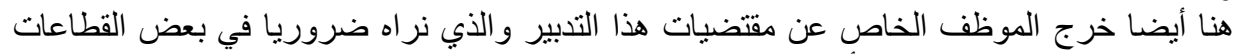
الاستر اتيجية خاصة إذا تعلق الأمر بموظفي البنوك و الذي قصر هذي هذا الاجر اء بالنسبة لهم على محافظ

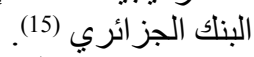

\section{مشأركة مدير البنك التوب}

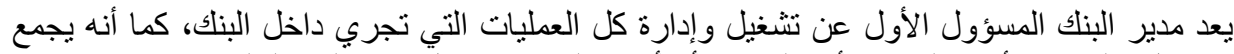

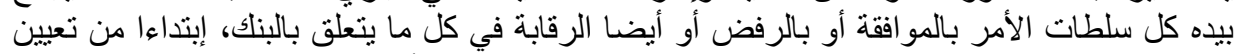

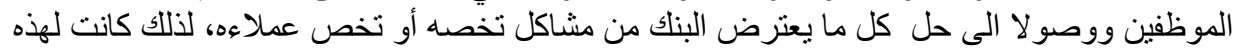

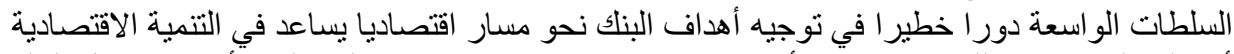

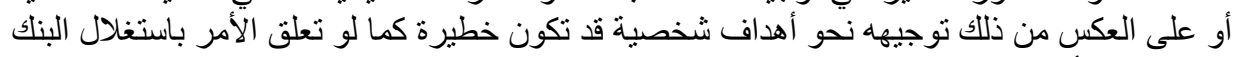

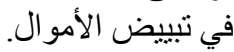

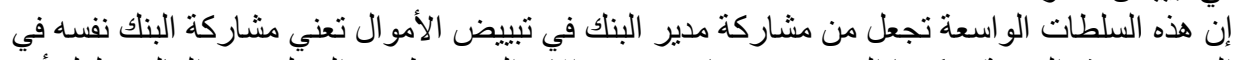

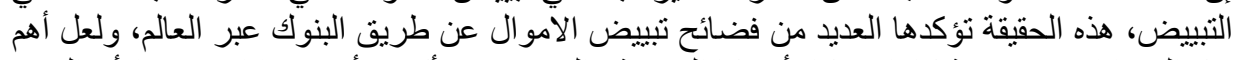

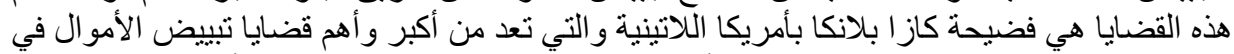

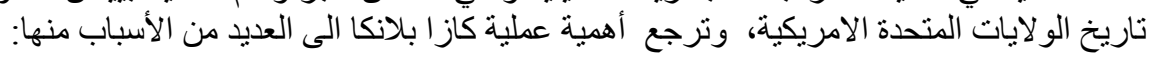

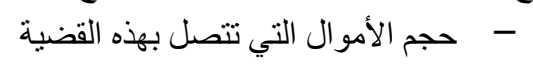

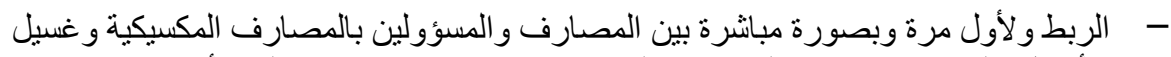

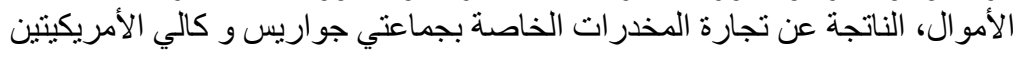

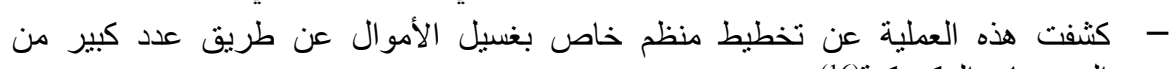

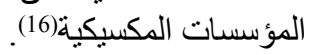

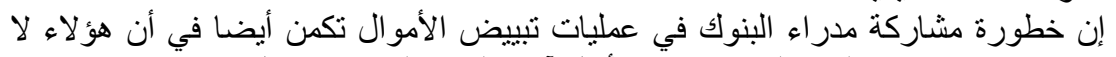

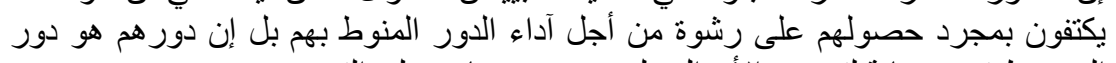

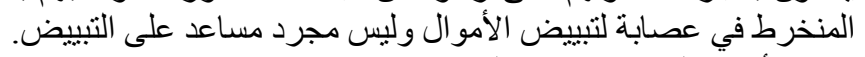
وتكمن أهمية التفرقة هنا فيما يلي: الاهري

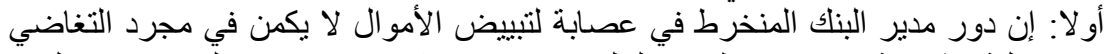

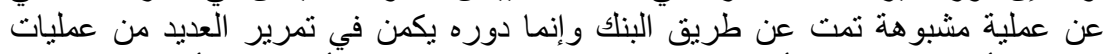

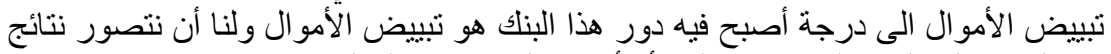

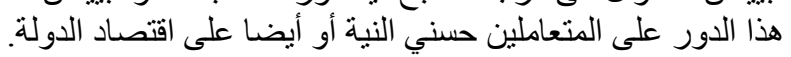

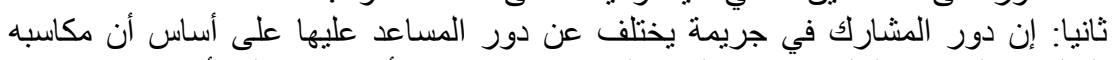

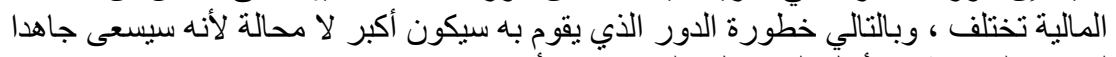

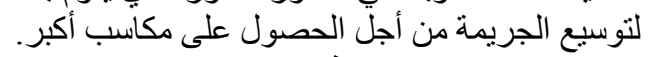

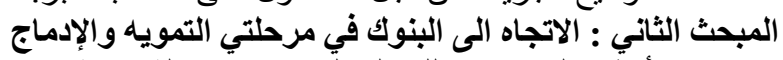

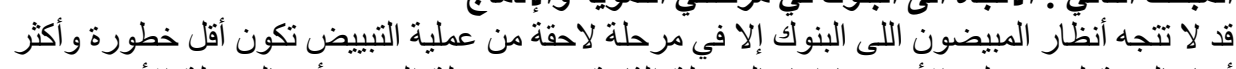

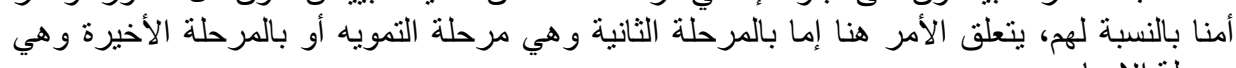

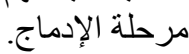




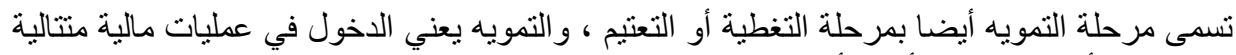

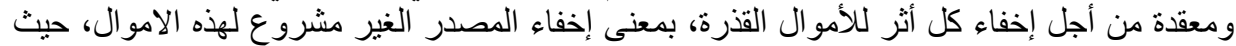

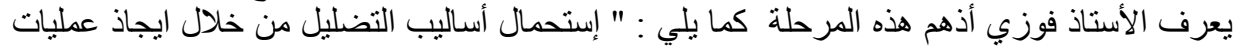

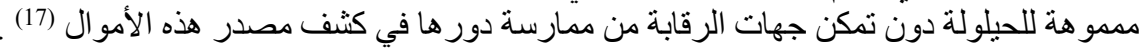

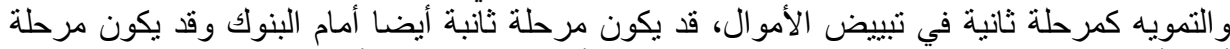

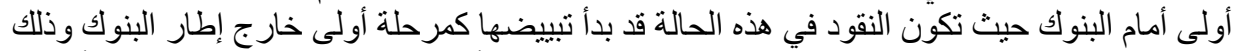

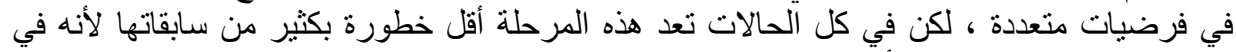

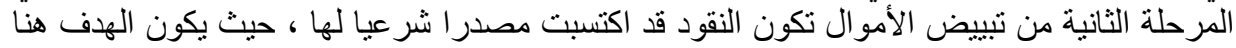

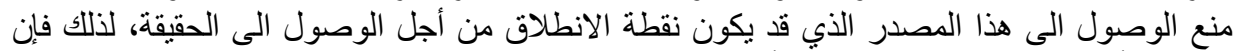

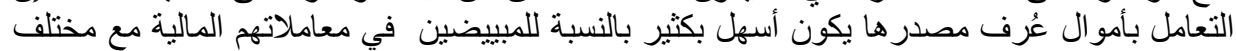

الأشخاص الطبيعية و المعنوية.

الفرع الأول: التمويه مرحلة أولى أمام البنوك

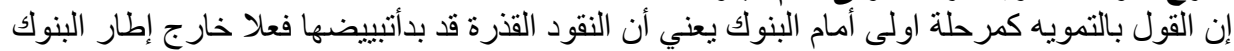

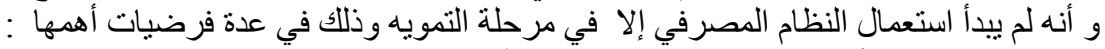
1 - تيبيض الأموال عن طريق تهريب العملة:

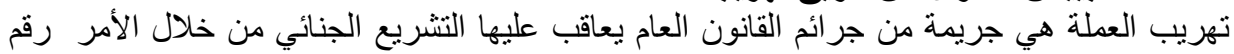

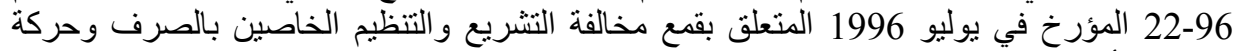
رؤوس الأموال من و إلى في الخار ج المعدل و المنمم. (18)

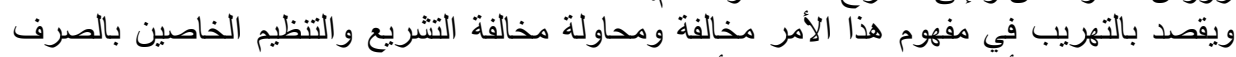

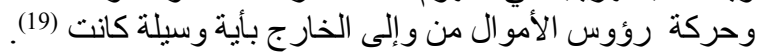

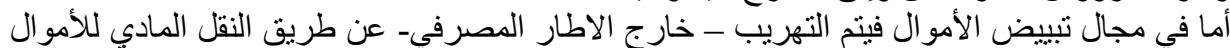

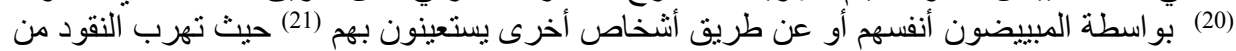
بلد الى آخر باستعمال طرف متعددة تذكر منها:

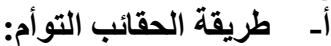

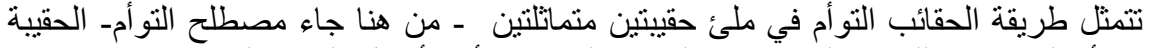

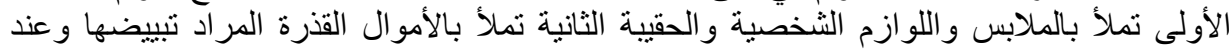

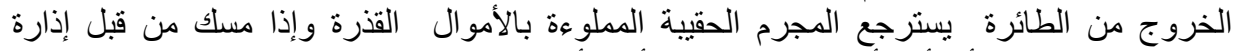

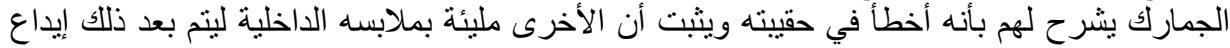
هذه النقود في بنوك خارجية كمرحلة ثانية (22).

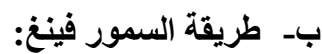

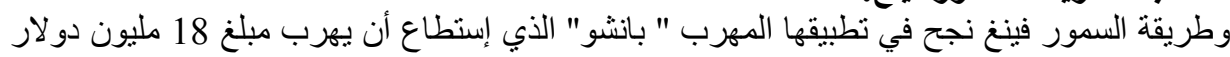

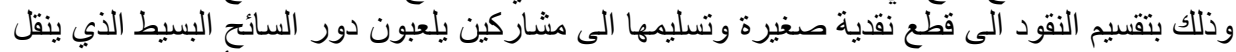

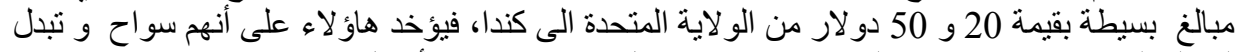

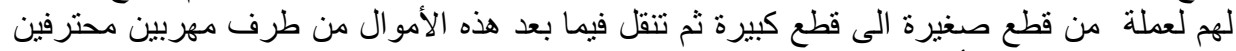

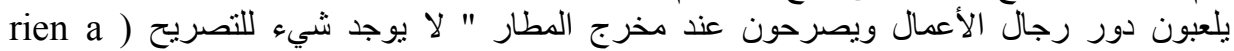
(23) " (déclarer

2- طريقة إحداث مناز عات قضائية وهية:

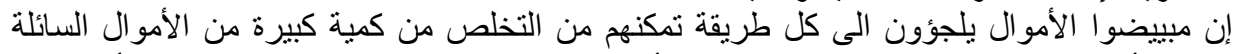

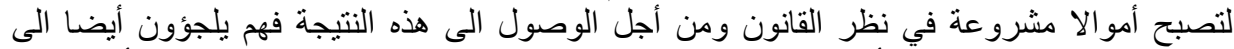

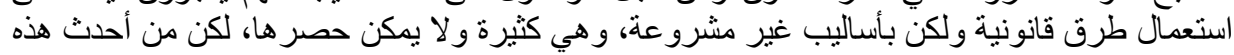




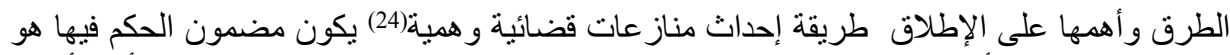

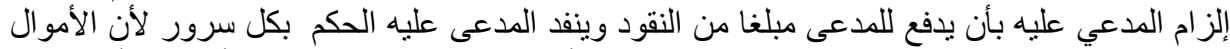

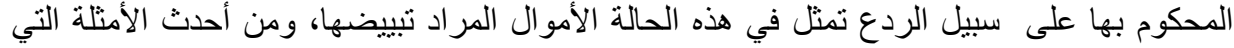

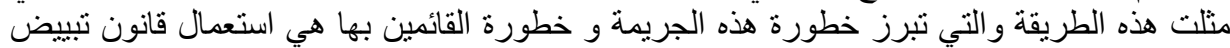

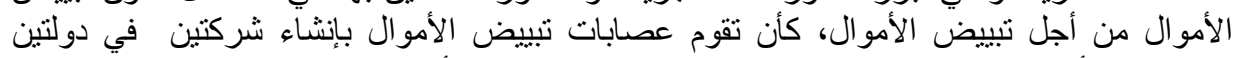

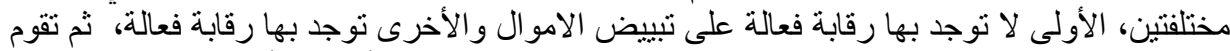

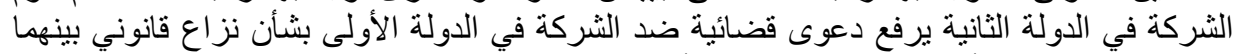

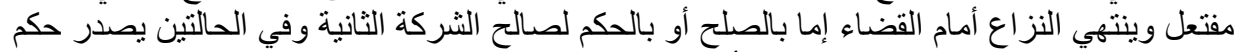

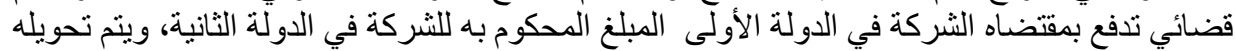
اليها عن طريق إحدى البنوك (25).

3- تبييض الاموال عن طريق أعمال التصاميم:

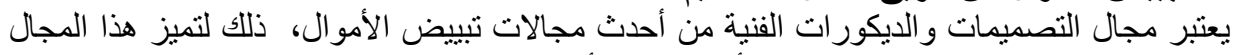

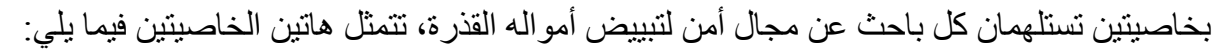

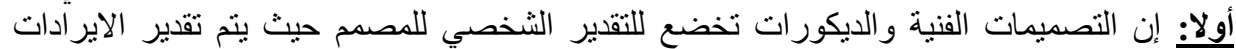

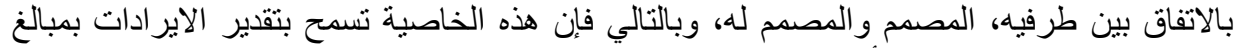

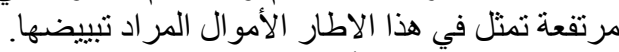

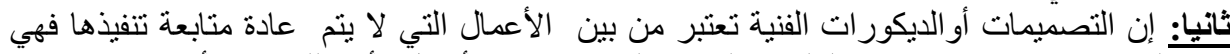

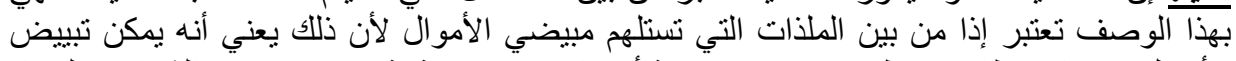

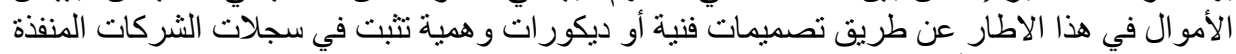

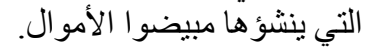

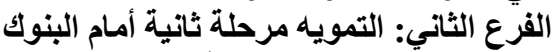

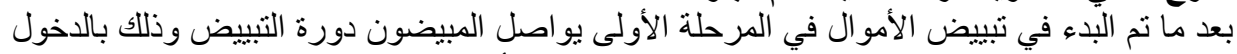

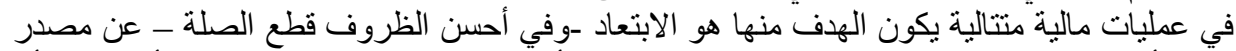

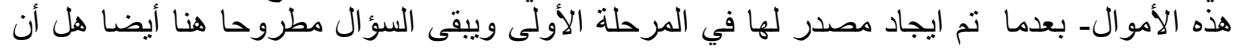

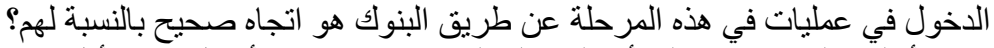

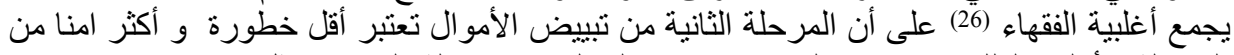

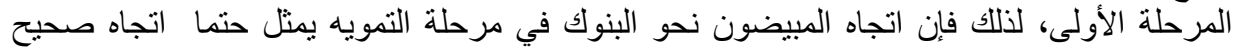

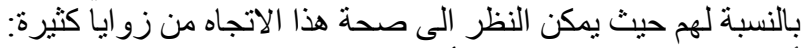

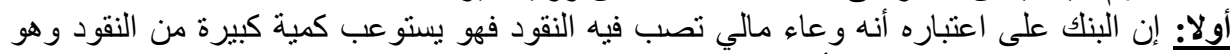

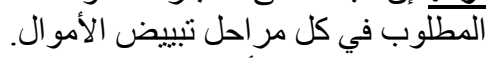

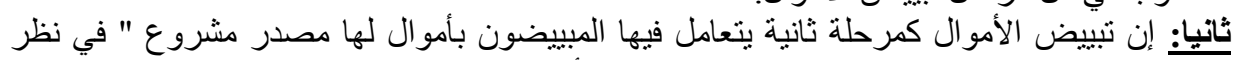

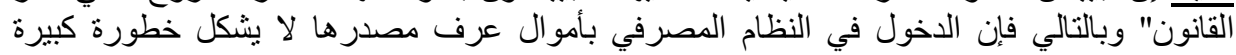

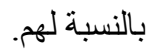

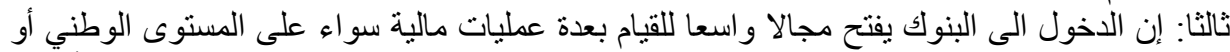

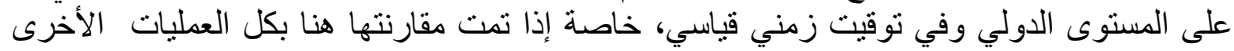

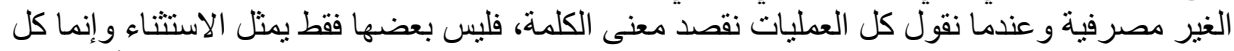
العطليات تحقق معنى الكلمة في هذا الاطار و و بجملة واحدة نقول: " إن البنوك تمثل الاتجاه الأسرع في

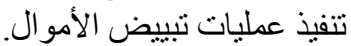
المطلب الثاني: مرحلة الادماج

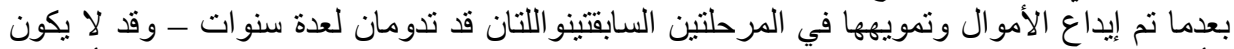
الأمر كذلك إذا استعمل النظام المصرفي مثلا عن طريق بعض العض العطليات التي تعتبر سريعة أو حتى لأى 


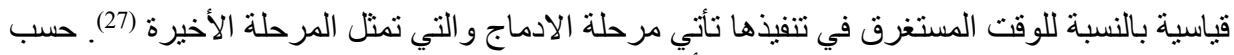

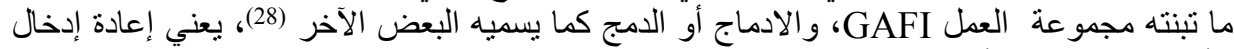

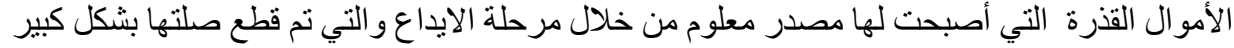

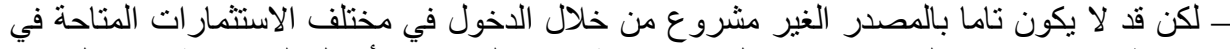

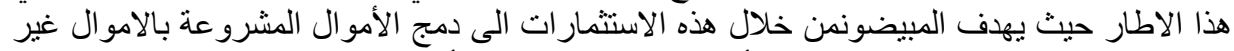

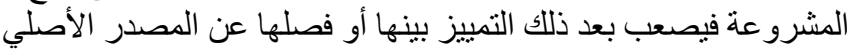

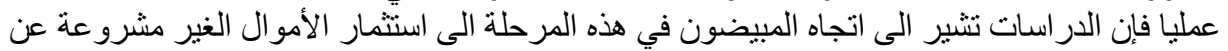

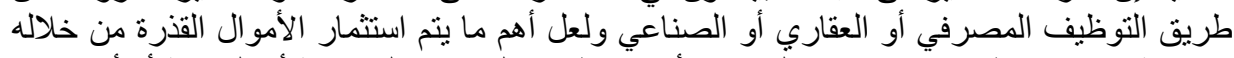

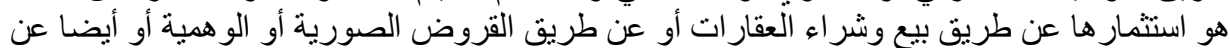

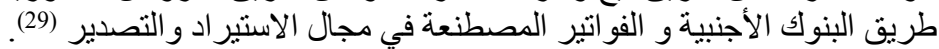

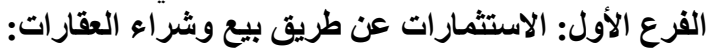

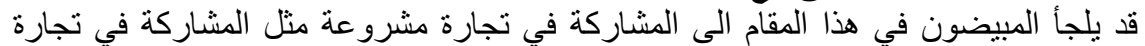

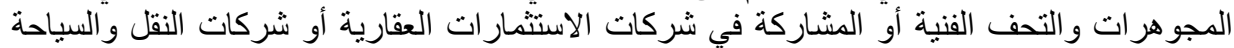

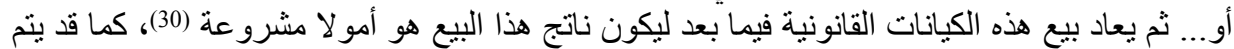

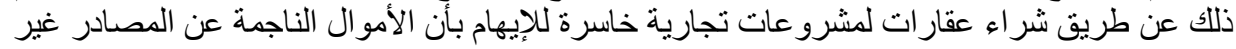
المشرو عة لها علاقة بهذه المشرو عات التشئ الخاسرة.

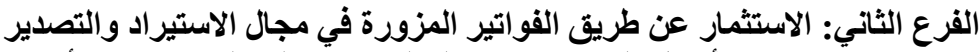

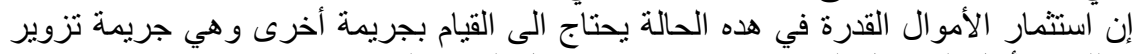

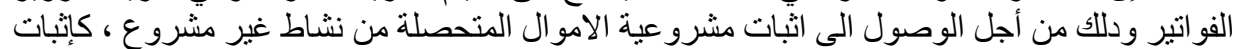

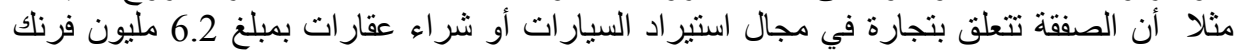

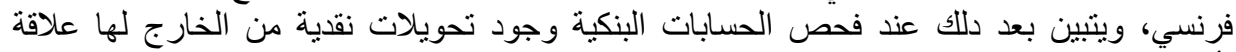

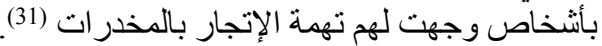

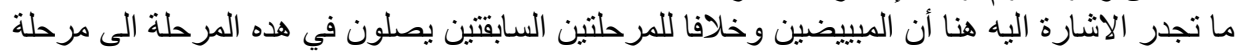

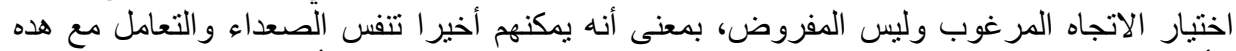

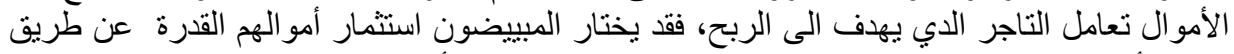

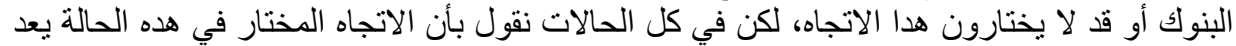

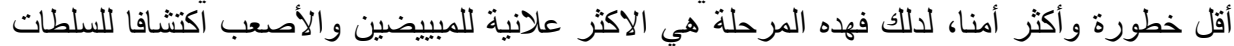
المختصة لأن الاموال القدرة في هده المرحلة تكون قد خرجت من اطار اللامشروعية ودخلت في الطار

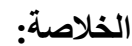

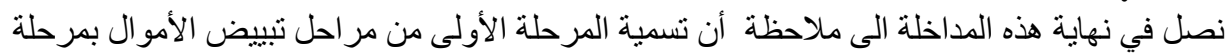

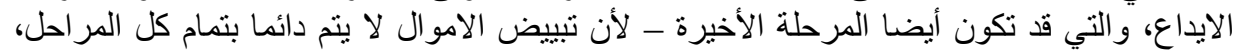

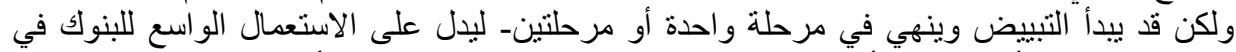

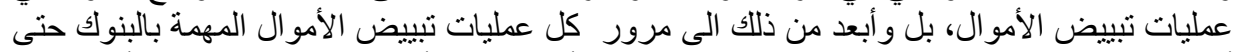

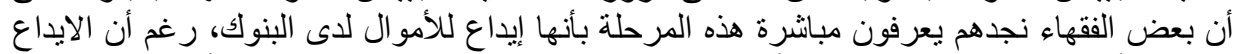

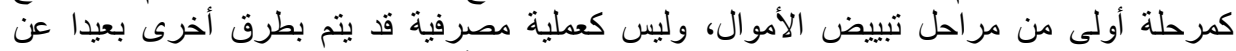

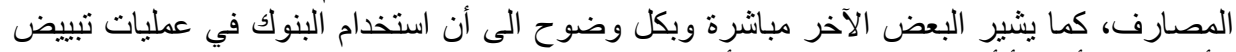

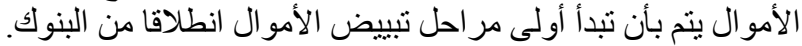

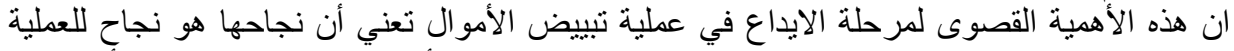

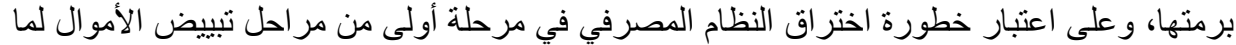

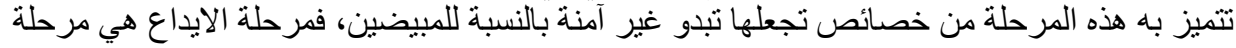


ايداع أمو ال سائلة وهي مرحلة ايداع أمو ال ناتجة عن الجريمة و هي أيضا مرحلة إيداع أموال بدون

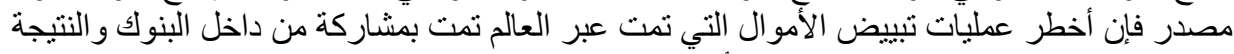

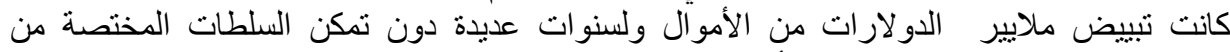

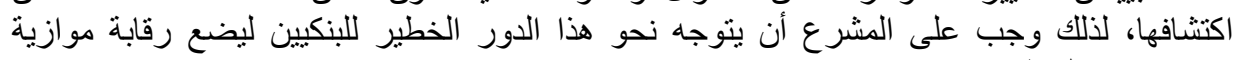
تضاهي هذه الخطورة.

لاحظنا أيضا من خلال بحث هده المر احل أن أهم إثكالية تواجه مبيضي الأموال هي إثنكالية الأموال السائلة

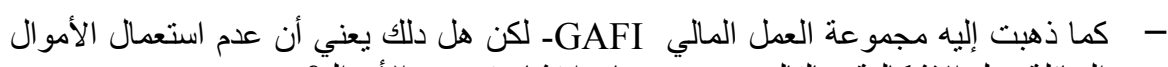

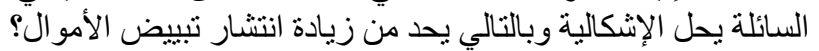

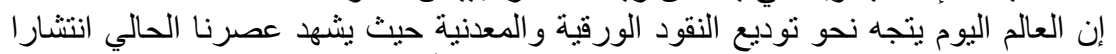

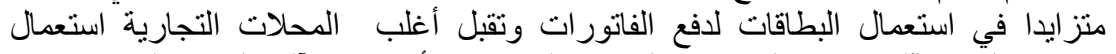

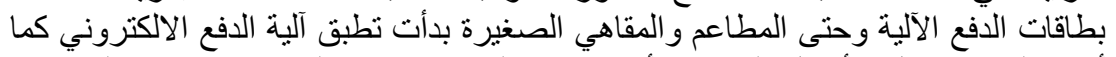

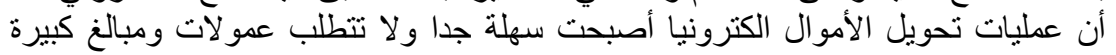

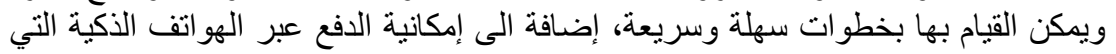

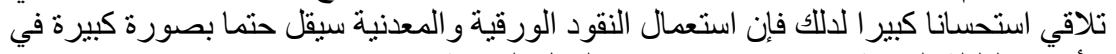

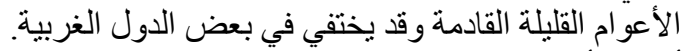

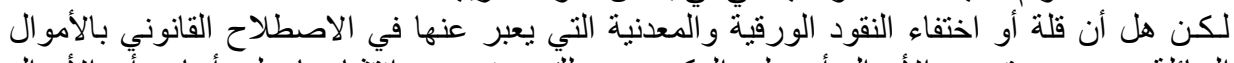

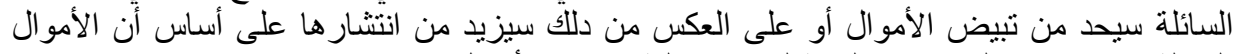

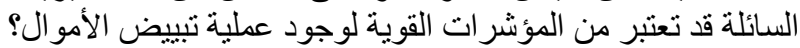

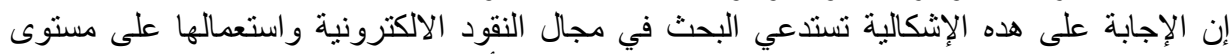

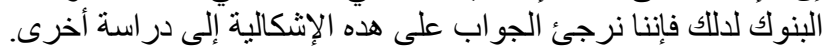

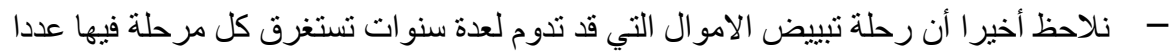

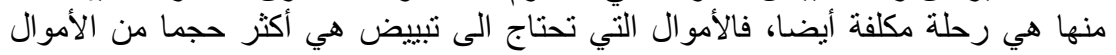

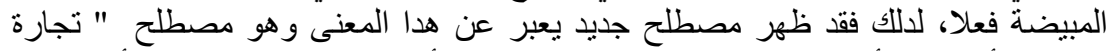

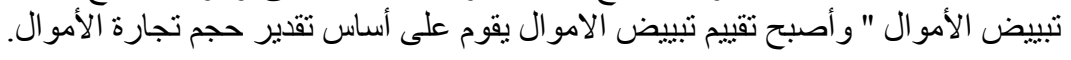

(1) -GAFI: www.fategafi.org

(2) عبد الفتاح سليمان، مكافحة غسل الأموال، الطبعة الثانية ،منثأة المعارف بالاسكندرية،

(3) عبد الفتاح سليمان، مكافحة غسل الأموال، المرجع السابق، ص 148 (3)

(4) Olivier jerez, le blanchement de largent, Revue banque , $2^{\text {eme }}$ edition,1998,p 127.

(5) سمير الخطيب، مكافحة عمليات غسل الأموال، منشأة المعارف بالاسكندرية، 2007،

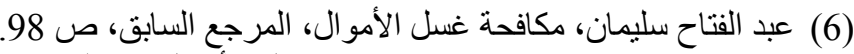

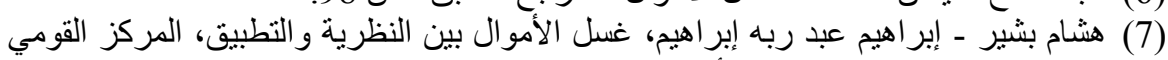

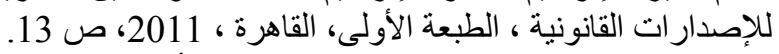

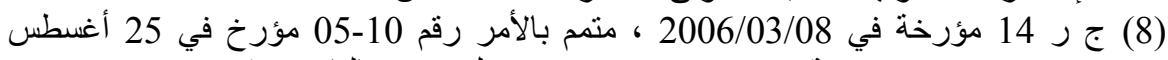

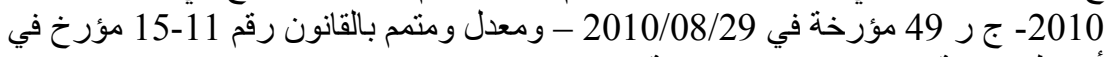

أغسطس سنة 2011- جر 44 مؤرخة في 2011/08/10. 
(9) المادة 40 من القانون 06-01، المؤرخ في: 20 فبراير 2006، يتعلق: بالوقاية من الفساد

ومكافحته المعدل و المتمح.

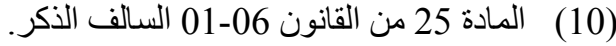

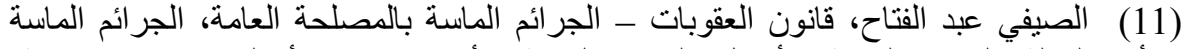

بأمن الدولة، الجر ائم الماسة بالأمو ال، الجر ائم الماسة بالأشخاص-، منشأة المعارف الإسة الاكندرية،

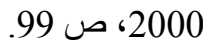

(12) https://ar.m.wikipedia.org $>13$ wiki> .... جر ائم

(13) المادة 40 و المادة 25 من القانون 06-01-01 السالف الذكر .

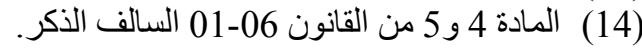

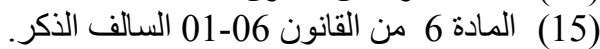

(11) هشام بشير إبر اهيم عبد ربه إبؤاهيم، غسل الأمو ال بين النظرية والتطبيق، مرجع سابق، ص

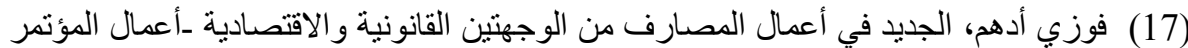

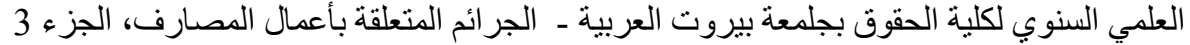

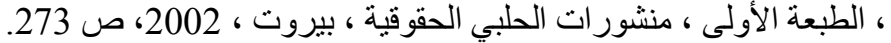

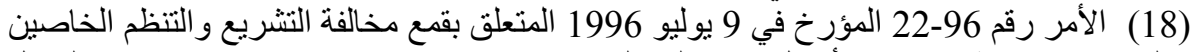

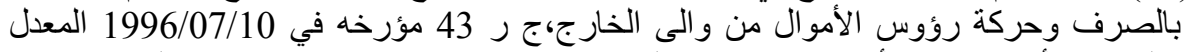

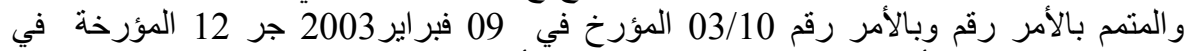

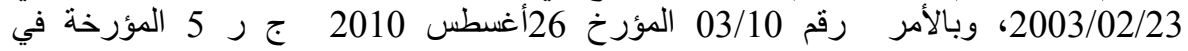

$.2010 / 09 / 1$

(19) المادة الأولى من الأمر سالف الذكر.

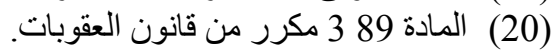

(21) FAVIANNE HATEM, Contraintes Fiscales, comportement stratégi ques des acteurs developement des paradis Fiscaux ,Fondemants, un jeux et limites, thése pour le doctorat en sciences économiques, université PANTHEON - ASSAS , 2003 P 331.

(22) FAVIANNE HATEMK, Contraintes Fiscales. Op cit p 332.

(23) OliviER JEREZ. le blanchement de largent, Op cit, P 129.

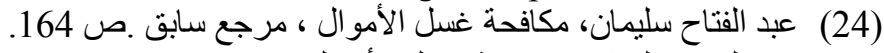

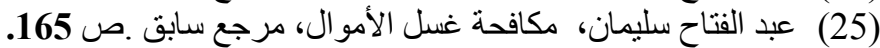

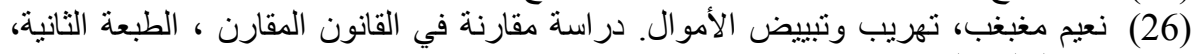

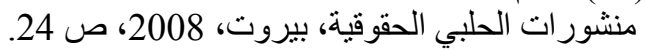

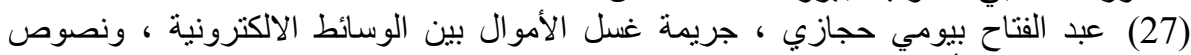

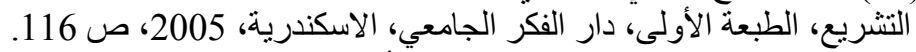

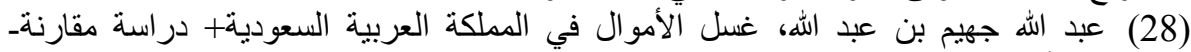

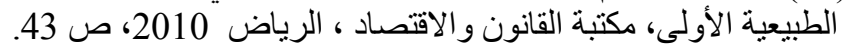

(29) هثام بشير إبر اهيم عبد ربه إبؤاهيم، غسل الأموال بين النظرية و التطبيق، مرجع سابق، ص

16.

(30) هام بشير إبر اهيم عبد ربه إبؤاهيم، غسل الأموال بين النظرية والتطبيق، مرجع سابق، ص

(31) هثام بشير إبر اهيم عبد ربه إبؤاهيم، غسل الأموال بين النظرية والتطبيق، مرجع سابق، ص 
- - عبد الفتاح سليمان مكافحة غسل الأموال، منثأة الطبعة الثانة منشأة المعارف الاسكندرية

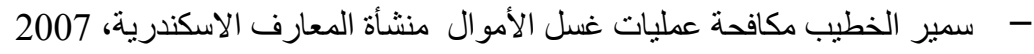

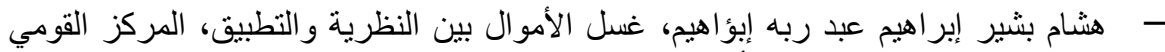
للإصدار ات القانونية الطبعة الأولى القاهرة ، 2011

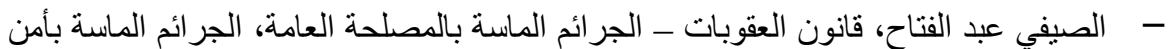

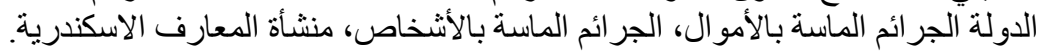

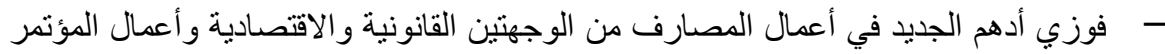

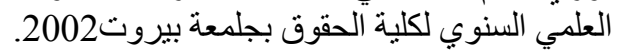

- - نعيم مغبغ، تهريب وتبيض الأموال. دراسة مقارنة في القانون المقارن ، الطبعة الثانية

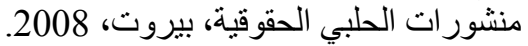

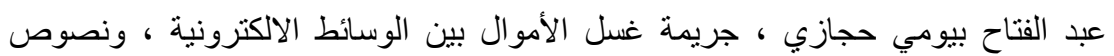

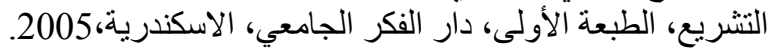

- - عبد الله جهيم بن عبد الله غسل الأموال الأل في الهملكة العربية السعودية+ دراسة مقارنة.

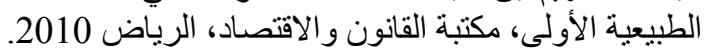

- FAVIANNE HATEM, Contraintes Fiscales, comportement stratégi ques des acteurs developement des paradis Fiscaux ,Fondemants, un jeux et limites, thése pour le doctorat en sciences économiques, université PANTHEON - ASSAS.

- Olivier jerez, le blanchement de largent, Revue banque , $2^{\text {eme }}$ edition,1998.

- GAFI: www.fategafi.org.

\section{المواقع الإكترونية}

- $\quad$ https://ar.m.wikipedia.org $>13$ wiki $>$ جر ائم 